\title{
Mining Social Data to Identifying User Behavior in Medhelp Forum on Health-Related Topics
}

\author{
V.Vijeya Kaveri, V.Maheswari
}

\begin{abstract}
Online life is a stage wherein customers can make content material fabric, talks, criticism, websites, commercial center, etc., in which individuals have a sentiment that it is progressively advantageous (or shaky) depending on the use and it's far a surroundings for network arranges as appropriately. It has empowered people to uncover their private wellness stresses and remarkable assessments on begging to be proven wrong issues of general wellbeing. In front line years, further to the general long range interpersonal communication web net sites like facebook, Twitter, Google+, etc., some of online human services net sites, close by MedHelp, sufferers Like Me, support, and wellness fundamental, which adapt to clients with exact clinical inconveniences, are additionally developing. for example, in web-based social networking framework like discussions and surveys the customers attempt to unite with equivalent companions or online therapeutic experts in responding to questions on the whole with, 'Am I ordinary, or do others revel in comparable signs and manifestations?' and 'Am I managing this side effect appropirately?' and 'How do people like me control this treatment viewpoint impact?' . in this paper we have were given were given focused on the most proficient method to find the customer direct in MedHelp discourse dialog board identifying with wellness subjects.
\end{abstract}

Keywords-Social Media, User Behavior, MedHelp, Health topics.

\section{INTRODUCTION}

online networking has was a primary a chunk of human presence and except inescapable. Correspondence has grow to be faster and the arena has contracted with the touchdown of net primarily based existence. It gives an splendid diploma for sharing statistics paying little apprehend to time and territory. net primarily based totally existence is a web primarily based stage to inspire social affiliation amongst a incredible amassing of human beings as device community. casual conversation sites (SNS) had been usually characterized as internet - based totally scenario in which human beings can make their non-public non-open profile and can set up a tool network with numerous customers dependent on their profile coordinating. on-line lifestyles has disillusioned the way wherein individuals unveil their very personal nicely-being issues and particular tests on with out trouble hooked up wrong elegant medical problems. It gives a one of a kind diploma for trading properly being statistics without the breaking factor of time and region. We take into account that on-line arranges firmly affect our dispositions, acknowledgment and conduct. This paper makes a robust point of the exceptional method to appearance the customer behavior on MedHelp discussion board.

MedHelp is an American person association maximum sincerely understood online discourse talk, installation in February 1994. one of the soonest spearheaded inside the area of client wellness statistics and gatherings on the net, earlier than the muse of WebMD, Microsoft or Yahoo. In extra of 15 million enlisted clients of the internet site had been there at some point of the exploration time body.

MedHelp is one of the first and exceptional perceived level on-line sheets committed for supporting customer orientated discourses on well being or scientific issues. In MedHelp there are five distinct customer gatherings: (1) health groups (medicinal manual networks), (2) international discussions, (three) ask-a-expert alternate board ,4) client agencies and (five) gatherings on pets. among these 5 organizations, "Ask a health practitioner" gathering sheets, "fitness groups" discussions and "common boards" talk on human offerings topics together with reliance, excessively touchy response, chronic obstructive pneumonic ailment, maximum illnesses, elegance surgical treatment, dental, gastroenterology, gynecology, coronary coronary heart, hepatitis, apprehensive system technological information, weight lower, ladies' health , urology, etc., however that "health communities " and "man or woman agency offices" every encourage collaborations among sufferers and guardians which can be targeted on this exploration. It permits us to research man or woman's notion who takes detail in on line well-being talks with the useful resource of utilising way of breaking down the depiction content fabric tested within the patron made gatherings.

The inspirational conduct of the customers who take part in on line well-being alternate discussions like MedHelp and Twitter has been researched. In MedHelp the behavior has been identified via the use of perusing the portrayal of the publish within the customized purchaser gatherings and from the talk of disputable tweets thru substance assessment; which lets in the overseers or society or extraordinary organization of human beings to all of the much more likely seize the educational and enthusiastic dreams from clients factor of view. 


\section{Associated Works}

Regardless of the truth that net based completely existence has been broadly pursued by anybody regardless of sexual orientation, getting ready, race, nicely being notoriety, well-being care, Chous et al. (2009b); Fisher and Clayton (2012); Shaw and Johnson (2011) has stated that it's far exceedingly difficult to see clients' proposal and concept of sharing their person nicely-being information is positioned to be extreme .

Newman et al. (2011b) ; van der Velden and El Emam, (2013) ; Divecha et al. (2012) has expressed that human beings might pick out now not to find their nicely being statistics to one/three people apart from their circle of relatives and well-wishers . multiple sufferers like to speak about their restorative troubles up close to and personal or over phone. At lengthy final, they reasoned that a method named effect the executives endeavor to impact the recognitions people have approximately a few issue, an man or woman, or an event this is appeared as an critical problem on the equal time as sharing nicely being realities via web-based networking media locales.

Santosh Kumar et al. (2016) has communicated that distinguishing the behavior of the clients thru on-line structures administration net primarily based lifestyles is a tough errand. they have got exhibited the empherical spoil down of some of the principle sides of clients behavior on lengthy range informal communication providing many thrilling elements of this fashion of customers conduct. in their exam paintings they have got completed an examination on the maximum talented method to execute teaching and studying method in flexible via the use of the internet based totally life advancements. George W. Kibirige (2016) has George W. Kibirige (2016) has diagnosed great human modern-day of behavior and as belief approximately them basically depending on their sex and age.

Hajra Waheed et al. (2016) have set their aim to supply studies inquiries to distinguish, have a take a look at and institution the traits associated with the client conduct. Tingan Tang et al. (2011) has referenced that describing purchaser conduct by means of the usage of using the usage of interpersonal employer life has been an keen checks locale for an extensive stretch. Liliana Laranjo et al. (2014) have surveyed the use and sufficiency of interventions the use of individual to person communique web web sites (SNSs) to exchange fitness practices.

Attard, An et al. (2012) has stated that humans who have been having inconveniences in their well-being situations had been bolstered by way of the usage of on line gatherings with the manual of offering well being proposals. Lu Yingjie et al. (2017) has expressed that medicinal offerings advantages in internet based existence has been used for giving well being statistics and passionate verbal exchange amongst precise types of customers, nearby patients, parental figures, and well being specialists.

\section{Building Personalised Consumer Organizations On Medhelp}

by and massive, well-being sheets are useful for converting wellness facts and rendering passionate course to part of the sufferers however overseers. MedHelp as of now offers lots of predefined rundown of gatherings, frequently prepared essentially depending on positive afflictions, clinical conditions, or remedy techniques for the increase of the clients.

what's greater, it lets in the customers to collect their customized customer bunches internal which humans may be a piece of and talk amongst themselves; installation the inquiry and collect response for them which help to understand their instructive and enthusiastic wishes from clients' component of view.

utilizing the precise dataset collected from MedHelp.org the social inclinations of customized clients has been diagnosed which determines the belief process in the back of structure altered custom designed consumer bunches in MedHelp in MedHelp via substance examination and as a result the very last outcomes with ordering the customized purchaser accumulating depending at the reason or use

\section{A. Information Description}

From MedHelp an informational index has been produced for a time of a twelve months through gathering all communicate load up posts and client profiles, which joins of in extra of 7,000,000 messages whole of each query and solutions posted with the asset of over one million actual customers in approximately 1.7 million strings. It consists of all posts in a from 320 pre-characterised gatherings and 857 consumer made customized gatherings, included at the characteristic of the profiles of 15, 07,357 clients who had allotted at any rate one message in the ones gatherings. From the above customers 7, 05,329 have been people of internet net website online on-line-characterized association and 11 , 434 had been benefactors of as a base one placed up in the collecting. most of the customers an entirety of one hundred and seventy,506 kinship connections existed among all clients, out of which $89.7 \%(131,753)$ have been used inside the dataset.

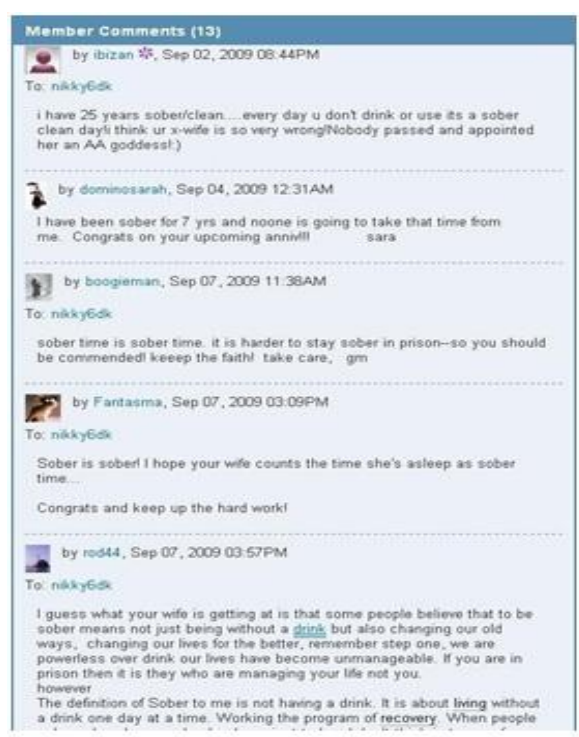

Figure 1. Sample Comments from MedHelp Forum 


\section{GROUPING PERSONALIZED USER GROUPS BY INTENTION}

Subjective substance examination has been practiced on arbitrarily picked tests of hundred customized client bunch with as far as possible now very little not exactly a hundred out of a gathering ; to infer a crude rundown of classifications as indicated by the depictions of the gatherings. The preparation has been finished with the assistance of ' $R$ ' programming.

The informational collection contains literary substance that conveys the remarks of the whole posts arbitrarily picked example obtained from MedHelp. The content record incorporates parameters like essayist who distributed the message or remarked, time stamp and portrayal of the remark; that is alluded as content 'corpora' is stacked for further content mining process. Subsequent to stacking the content, information preprocessing has been done, this at last gave a clean prepared content after evacuation of stop words, void areas and relational words.

Once, change and purging activities are done, the recurrence conveyances of the expressions are created as a grid group. At last the appraisal achieved top ten classes(user gatherings) in view of on their expression recurrence dissemination which may be graphically spoken to in figure 2 .

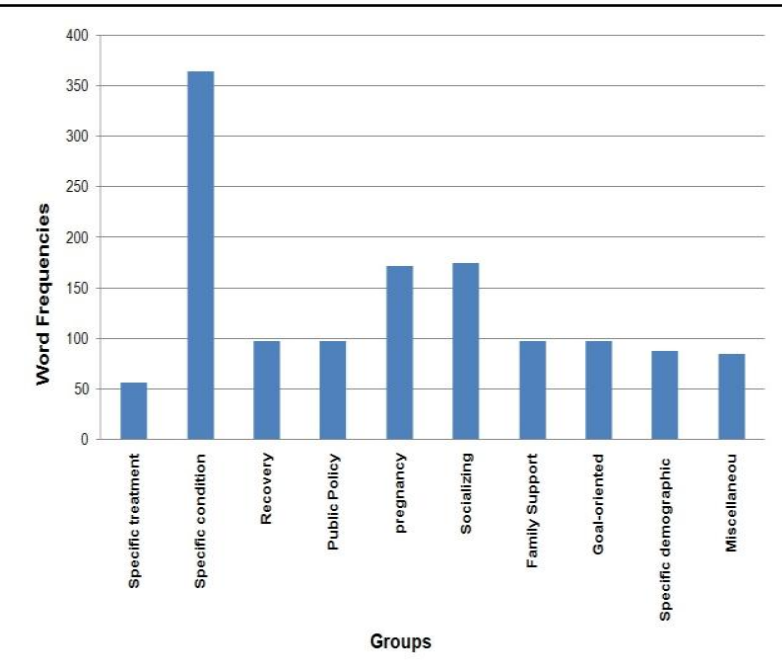

Figure 2. Personalized User Groups by Purpose

\section{REASONS FOR CREATING PERSONALIZED GROUPS}

figure 2 demonstrates that the classifications are not definitely unrelated and in this manner a community may be arranged underneath more than one category. On the overall, in multiple magnificence 89 (eleven.7\%) of character made gatherings and $25(8.6 \%)$ web page-characterised organizations have been ordered.

For a version at the same time as brooding about being pregnant-associated networks they have been notably more likely sexual orientation great by means of nature, which is excluded inside the specific socioeconomics/intercourse superbness. Non-English titles and depictions have been additionally looked after as random networks

The circulations of the ten site characterised gatherings and customized purchaser gatherings made had been condensed in table 1. among the web page-depicted gatherings, the two maximum not bizarre classes are those related with "exquisite situations" (class 2, 61.eight $\%$ ) and "being pregnant" (class five, 15\%).

table 1 seems about the magnificence conveyance of customized customer made gatherings from the default website-characterised gatherings. among the site-characterised accumulating and purchaser made custom designed bunch the fine elegance is "express situations", besides the rate stays drops to roughly $19 \%$.

Table 1. Category Distributions of site-defined and personalized user groups

\begin{tabular}{|l|c|c|}
\hline Category & $\begin{array}{l}\text { Site-defined } \\
\text { groups } \\
(\mathrm{n}=320)\end{array}$ & $\begin{array}{l}\text { Personalized } \\
\text { groups } \\
(\mathrm{n}=857)\end{array}$ \\
\hline 1.Specific treatment & $22(6.9 \%)$ & $57(6.6 \%)$ \\
\hline 2.Specific condition & $198(61.8 \%)$ & $365(42.5 \%)$ \\
\hline 5.Pregnancy & $18(5.6 \%)$ & $172(20 \%)$ \\
\hline 6.Socializing & $40(12.5 \%)$ & $175(20.4 \%)$ \\
\hline 9.Demographics & $27(8.4 \%)$ & $88(10.2 \%)$ \\
\hline 10.Miscellaneous & $5(1.5 \%)$ & $85(9.9 \%)$ \\
\hline Others $(3,4,7,8)$ & $27(8.4 \%)$ & $98(11.4 \%)$ \\
\hline
\end{tabular}

desk 1 demonstrates that the second top magnificence of patron made collecting has been associated with "mingling " (magnificence 6). This collecting demonstrates that it's far labored to find out partners and to have connection in casual discussions spherical things that could or won't be diagnosed with well-being, as opposed to searching out information sort of their ailments and therapies.

some of the purchaser made gatherings, pregnancy-related amassing have an area with third pinnacle beauty which makes 20\% among the consumer made amassing. Our examination exhibits that this amassing predominantly centers round tendencies, for example, age, pregnancy-associated complexities, or request on tyke elevating and childcare.

additionally, in our informational index about eleven\% of the customer made gatherings have an area with statistic training. A large range of these get-togethers ( sixty nine\%) are related to a specific circumstance, pregnancy, or for mingling. as an instance, there are a few gatherings for sufferers who've an area with indistinguishable age amassing and district, or for young adults who face the unwell consequences of concoction awkwardness (mental imbalance) but they want to mingle and extent their contribution with each other. these bits of information spurred us to discover the reason inside the back of why the customers make customized gatherings notwithstanding the reality that they have got website online-characterised bunches . 
coming up subsequent are the motives

1. To shape customized consumer - bunches relying on complex manifestations, unusual and faster treatments.

2. To accomplice with equivalent socioeconomics peer members.

three. To hold up social connections.

four.To make copied bunches without distinguishing bunch presence.

\section{READING DIABETES CONVERSATIONS ON TWITTER \& RESULTS DISCUSSION}

A growing community of diabetic patients, human offerings organizations, specialists and associations proportion their perspectives in on line internet primarily based existence tiers recognized with diabetes. Twitter is one of the internet based totally totally lifestyles levels wherein humans percentage and unequivocal their emotions. for instance, there are real hashtags on Twitter, for instance, \#dsma, which speaks to "Diabetes Social Media Advocacy", it's far community where people find comparative patients, additionally they take part in viral correspondence and records sharing, and discover pal assist on-line.

Based on seek terms and hashtags relevant to diabetes tweets are recognized in the diabetes community. We have used the following query phrases and hashtags for retrieving, for e.g, "\#glucose", "\#blood glucose", "\#diabetes", "\#insulin pump”,"\#insulin”,“\#t1d”,“\#type1 diabetes”,"\#type1”, ”\#t2d”, "\#type2diabetes", “\#type2", “\#bloodsugar","\#dsma”. We have separated the tweet contents, username, timestamp, geo-region from the retrieved tweets. Table 2 shows the frequency of tweets and tweeting frequency of the user.

Table 2. Frequency of tweets and users

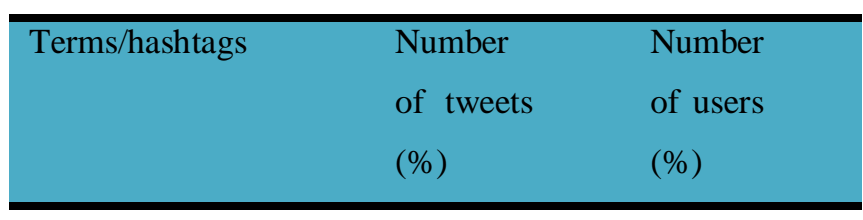

\begin{tabular}{|c|c|c|}
\hline Diabetes & $\begin{array}{l}1,700,268 \\
(90.99 \%)\end{array}$ & $\begin{array}{l}748,001 \\
(89.6 \%)\end{array}$ \\
\hline \#diabetes & $\begin{array}{r}155,868 \\
(8.34 \%)\end{array}$ & $\begin{array}{r}67,229 \\
(8.1 \%)\end{array}$ \\
\hline Insulin & $\begin{array}{r}93,820 \\
(5.0 \%)\end{array}$ & $\begin{array}{r}59,728 \\
(7.2 \%)\end{array}$ \\
\hline glucose & $\begin{array}{l}65,033 \\
(3.4 \%)\end{array}$ & $\begin{array}{l}46,357 \\
(5.6 \%)\end{array}$ \\
\hline \#doc & $\begin{array}{r}28,616 \\
(1.5 \%)\end{array}$ & $\begin{array}{r}16,457 \\
(2.0 \%)\end{array}$ \\
\hline \#dsma & $\begin{array}{l}11,957 \\
(0.6 \%)\end{array}$ & $\begin{array}{l}1,424 \\
(0.2 \%)\end{array}$ \\
\hline blood glucose & $\begin{array}{r}12,212 \\
(0.7 \%)\end{array}$ & $\begin{array}{l}6,904 \\
(0.8 \%)\end{array}$ \\
\hline$\# \mathrm{t} 1 \mathrm{~d}$ & $\begin{array}{l}, 040 \\
(0.3 \%)\end{array}$ & $\begin{array}{l}3,835 \\
(0.5 \%)\end{array}$ \\
\hline \#dblog & $\begin{array}{l}5,411 \\
(0.2 \%)\end{array}$ & $\begin{array}{l}1,132 \\
(0.1 \%)\end{array}$ \\
\hline insulin pump & $\begin{array}{l}5,159 \\
\quad(0.4 \%)\end{array}$ & $\begin{array}{l}4,061 \\
(0.5 \%)\end{array}$ \\
\hline
\end{tabular}

\begin{tabular}{||l||l||c||}
\hline \hline \#type1 & $\begin{array}{c}4,211 \\
(0.2 \%)\end{array}$ & $\begin{array}{c}1,800 \\
(0.2 \%)\end{array}$ \\
\hline \hline \multirow{3}{*}{ \#type2 } & 2,905 & 1,468 \\
& $(0.1 \%)$ & $(0.2 \%)$ \\
\hline \hline \#bgnow & 2,470 & 753 \\
& $(0.2 \%)$ & $(0.1 \%)$ \\
\hline \hline \multirow{2}{*}{ \#type1diabetes } & 1,812 & 1,248 \\
& $(0.1 \%)$ & $(0.1 \%)$ \\
\hline \hline \multirow{2}{*}{ \#bloodsugar } & 1,718 & 1,213 \\
& $(0.1 \%)$ & $(0.1 \%)$ \\
\hline \hline \multirow{2}{*}{ \#type2diabetes } & 1,388 & 1,035 \\
& $(0.1 \%)$ & $(0.1 \%)$ \\
\hline \hline \multirow{2}{*}{ \#t2d } & $\begin{array}{c}935 \\
(0.1 \%)\end{array}$ & $\begin{array}{c}452 \\
(0.1 \%)\end{array}$ \\
\hline
\end{tabular}

\section{CONCLUSION}

we have researched supporter's inspiration in taking part in online wellbeing related talks and portrayed their material occasions and arranged their characters in web based life stage. Our result shows that wellbeing related data infests internet based life. besides to inquiries concerning specific events and cure, clients inclination to associate with specific patients and parental figures in the indistinguishable statistic gathering or extent same interest or wellbeing wants.

\section{ACKNOWLEDGMENT}

This work has been carried out at DST-FIST sponsored Wireless Sensor Network and IOT Lab (order Sanction No.: SR/FST/ETI-413/2018Dated: 08th February, 2018), Department of Computer Science and Engineering, Sathyabama Institute of Science and Technology.

\section{REFERENCES}

1. Attard, An., and N.S. Coulson (2012),. "A Thematic assessment of affected person conversation in Parkinson's ailment on-line help enterprise dialogue forums." computers in Human behavior 28 (2): 500-506.

2. Chou, W. Y. S., Y. M. Chase, E. B. Beckjord, R. P. Moser, and B. W. Hesse (2009b), Social media use within the US: Implications for well-being correspondence, Jour-nal of scientific internet studies, 11 (four).

3. Divecha, Z., A. Divney, J. Ickovics, and T. Kershaw (2012), Tweeting approximately attempting out: do low-pay, little one rearing youths and younger grown-usautilize new media upgrades to impart about sexual well-being?, Perspect intercourse Reprod fitness, 44 (three), 176-eighty three.

4. Fisher, J., and M. Clayton (2012), Who gives a tweet: surveying patients' enthusiasm for the usage of net based lifestyles for social insurance, Worldviews Evid based totally completely Nurs, 9 (2), 100-108.

5. Hajra Waheed, Maria Anjum (2012), "examination of customer conduct on casual communique locales", PLoS ONE 12(2). 
6. Liliana Laranjo, Amae Arguel ," The impact of informal conversation locales on well-being behavior change: a methodical audit and meta-assessment",J Am Med data Assoc 2015;22:243 - 256 doi:10.1136/amiajnl-2014-002841.

7. Tingan Tang , Matti Hämäläinen(2011)," information purchaser behavior in a neighborhood Social Media Platform with the resource of Social network assessment", indTrek'11 September 28-30, 2011, Tampere, Finland.Copyright $2011 \quad$ ACM 978-1-4503-0816-8/11/09.

8. Newman, M. W., D. Lauterbach, S. A. Munson, P. Resnick, and M. E. Morris (2011b), it is now not that I do now not have issues, i'm definitely now not placing them on facebook: chal-lenges and openings in utilising on the internet informal businesses for properly being, in lawsuits of the ACM 2011 amassing on pc upheld agreeable art work, pp. 341-350, ACM.

9. van der Velden, M., and ok. El Emam (2013), "now not each in reality considered one of my companions want to realise": a subjective research of excessive college sufferers, protection, and net based life, J Am Med tell Assoc, 20 (1), sixteen-24.

10. V.Vijeya Kaveri and V.Maheswari (2017), "A Framework for Recommending fitness-related topics primarily based on subject remember Modeling in Conversational facts(Twitter)", Springer, Cluster Computing (CLUS) , ISSN online : 1573-7543.

11. Aramaki, E., S. Maskawa, and M. Morita (2011), Twitter receives the $u$ : figuring out in uenza pestilences utilizing twitter, in court cases of the collection on true techniques in normal language managing, pp. 1568-1576.

12. Bian, J., U. Topaloglu, and F. Yu (2012), closer to huge scale twitter digging for medicine related antagonistic activities, in lawsuits of the 2012 worldwide workshop on clever properly being and prosperity, pp. 25-32, ACM.

\section{AUTHORS PROFILE}

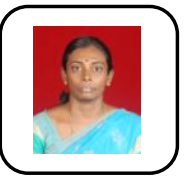

V. Vijeya Kaveri, Research Scholar, School of Computing, Sathyabama Institute of Science and Technology. Her research work is in the area of Mining Social Data to identifying user behavior in MedHelp forum on health-related topics

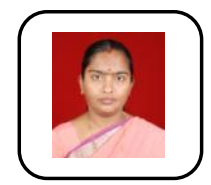

Dr.V.Maheswari is currently working as Professor, Department of Computer Science and Engineering, Saveetha Engineering College. She has got teaching experience of more than 21 years. She received her Bachelor Degree in Computer Science and Engineering from Madurai Kamaraj University. She got her Masters Degree in Computer Science and Engineering from Madras University and is a university second rank holder. She got her doctoral degree in Computer Science and Engineering in the area of Network Security. 